\title{
OCEANOGRAPHIC TEST FACILITY AT DUCK PIER, NC
}

\section{C.E. Woody, R. Dagnall, and E. Michelena}

\author{
National Data Buoy Center \\ Stennis Space Center, MS 39529-6000
}

D. McGehee and G. Bichner
The National Data Buoy Center (NDBC), U.S. Army Corps of Engineers (COE) Waterways Experiment Station (WES) and National Ocean Service (NOS) have established an environmental test facility for ocean and atmospheric sensors at the WES Field Research Facility (FRF) in Duck, NC. This facility provides a natural environmental laboratory for testing and evaluating sensors used for long-term, remote monitoring on platforms of opportunity. NDBC, NOS, and WES operate national scale-monitoring networks extending from estuaries through the coastal zone to offshore, each using its own unique platforms to accomplish agency missions. It is important that these platforms have the capability to accept additional sensors and can manage (process, qualify, store, and maintain) and disseminate the data in real time. The environmental test facility on the FRF pier is shared between the participating agencies. The new facility consists of an NDBC coastal weather station, two laboratories housing wet and dry laboratory facilities, an ocean platform for supporting sensors underwater, WES directional waves, water pressure, and current sensors, and a water level station operated by NOS. This facility will enable environmental managers and scientists to assess and evaluate the capabilities of environmental sensors to meet the requirements for accurate, reliable long-term unattended monitoring programs.

\section{INTRODUCTION}

The need for long-term, continuous monitoring of the marine environment, particularly in coastal waters, was established through several fora, one being a workshop hosted by NOS and NDBC in July 1994. The primary goals of the workshop were to identify, prioritize, and ensure the suitability of ocean measurements that could be made from established ocean platforms. Measurements were prioritized as to their feasibility and need for development. In addition, consideration was given to durability of the sensors and their design, power consumption, size maintenance, cost, and data flow. The results of the workshop are summarized in Fig. 1.

Two important results of the workshop were 1) the identification of the need for a standard interface allowing an investigator to integrate his instrument into an available platform with little modification and 2) an ocean sensor test facility. As a starting point, three organizations operating marine platforms for long-term monitoring of environmental parameters were identified. These are NOS, WES, and NDBC, each with its specific mission, unique platform, and expertise developed to cope with the physical environment (Fig 2). Each operates national scale-monitoring networks extending from estuaries through the coastal zone to offshore. An effective approach then

\author{
Army Corps of Engineers \\ Duck, NC 27949
}

\author{
T. Mero \\ National Ocean Service
Silver Spring, MD 20910
}

\begin{tabular}{|c|l|l|}
\hline CAN MEASURE & HIGH PRIORITY & \multicolumn{1}{|c|}{ MEDIUM PRIORITY } \\
\hline NOW & $\begin{array}{l}\text { VELOCITY } \\
\text { TEMPERATURE } \\
\text { SALINITY }\end{array}$ & $\begin{array}{l}\text { FLUOROMETRY } \\
\text { SOLAR RADIATION } \\
\text { PHOTOSYNTHETIC } \\
\text { AVALABLE RADIATION } \\
\text { TRANSMISSIVITY } \\
\text { PRECIPITATION }\end{array}$ \\
\hline $\begin{array}{c}\text { WITH } \\
\text { REASONABLE } \\
\text { DEVELOPMENT }\end{array}$ & $\mathrm{CO}_{2}$ & $\begin{array}{l}\text { NUTRIENTS } \\
\text { ZOOPLANKTON } \\
\text { DISSOLVED OXYGEN } \\
\text { TOMOGRAPHY }\end{array}$ \\
\hline
\end{tabular}

Fig. 1. Summary of results of NDBC workshop on oceanographic measurements

is to use the existing capability, infrastructure, and platforms of these networks. The requirement for a controlled accessible research facility to bring together the established base and new technologies for evaluation became paramount.

The FRF pier in Duck, NC (Fig. 3), was selected as the ocean sensor test site. A cooperative working agreement was established by NOS, WES, and NDBC. Each group has their own platform on or near the pier. This facilitates testing of sensors and their integration into the various types of platforms being used and provides a vehicle for intercomparison of techniques and technology.

\section{FRF PIER}

The FRF is part of the WES Coastal and Hydraulics Laboratory (C\&HL). It is on 175 acres, has a $561-\mathrm{m}$ pier extending into the Atlantic Ocean, and is along a 100-km stretch of unbroken coastline. It serves as a field base for atmospheric and oceanic studies (Birkemeier, 1985) and is an excellent field facility for testing and evaluating new instrumentation. With the spacious grounds and the platform the pier provides over the surf zone, the FRF hosts a variety of research efforts and provides a secure location for research opportunities in the future. Commercial and generator power and communications are available on the pier as well as sections of the grounds. More information on the pier can be found on the Internet at http://www.frf.usace.army.mil.

\section{PLATFORM AVAILABILITY}

\section{A. NOS Network}

NOS, a part of the National Oceanic and Atmospheric Administration (NOAA), operates a network of approximately 


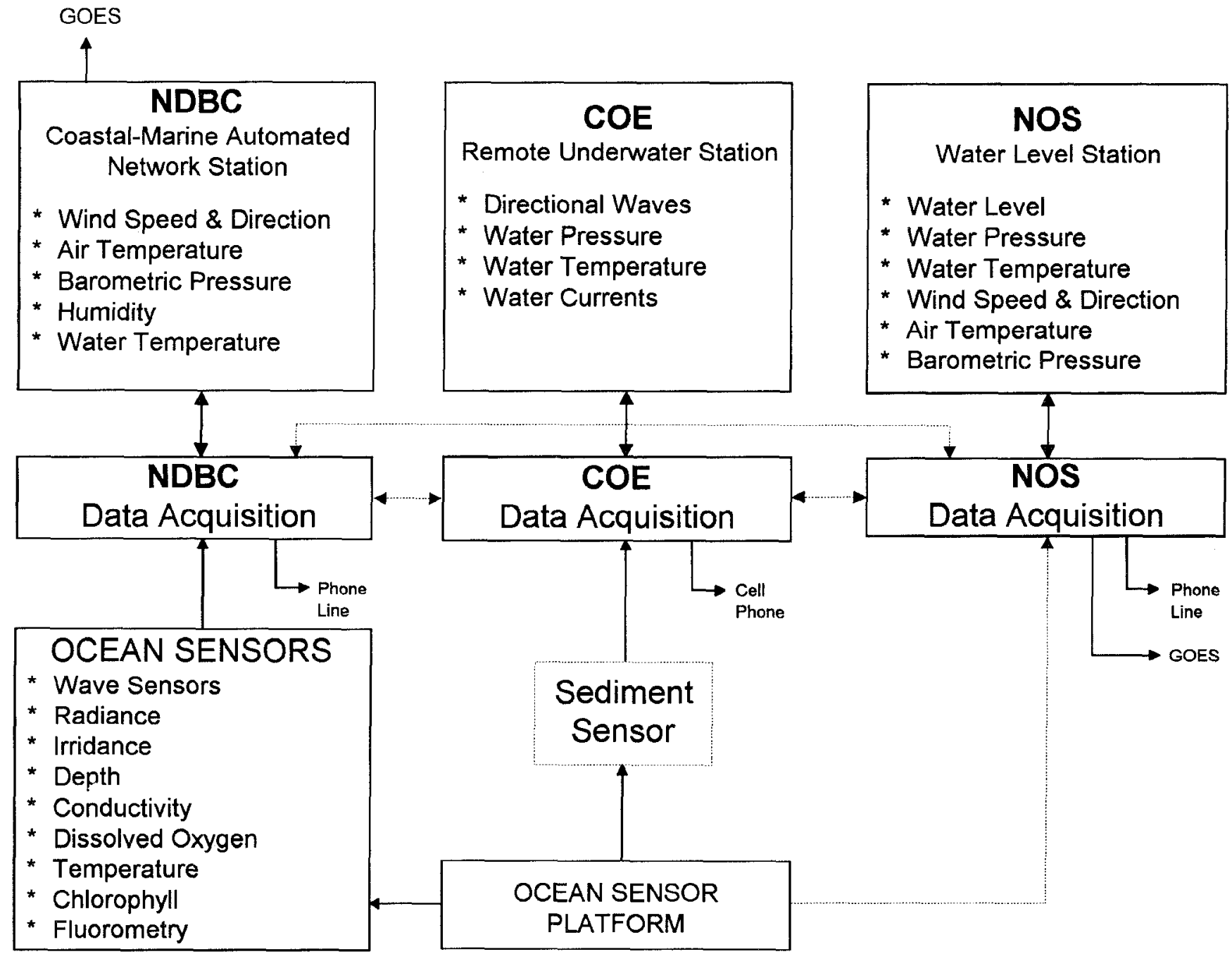

Fig. 2. Environmental measurements made by NDBC, COE, and NWS
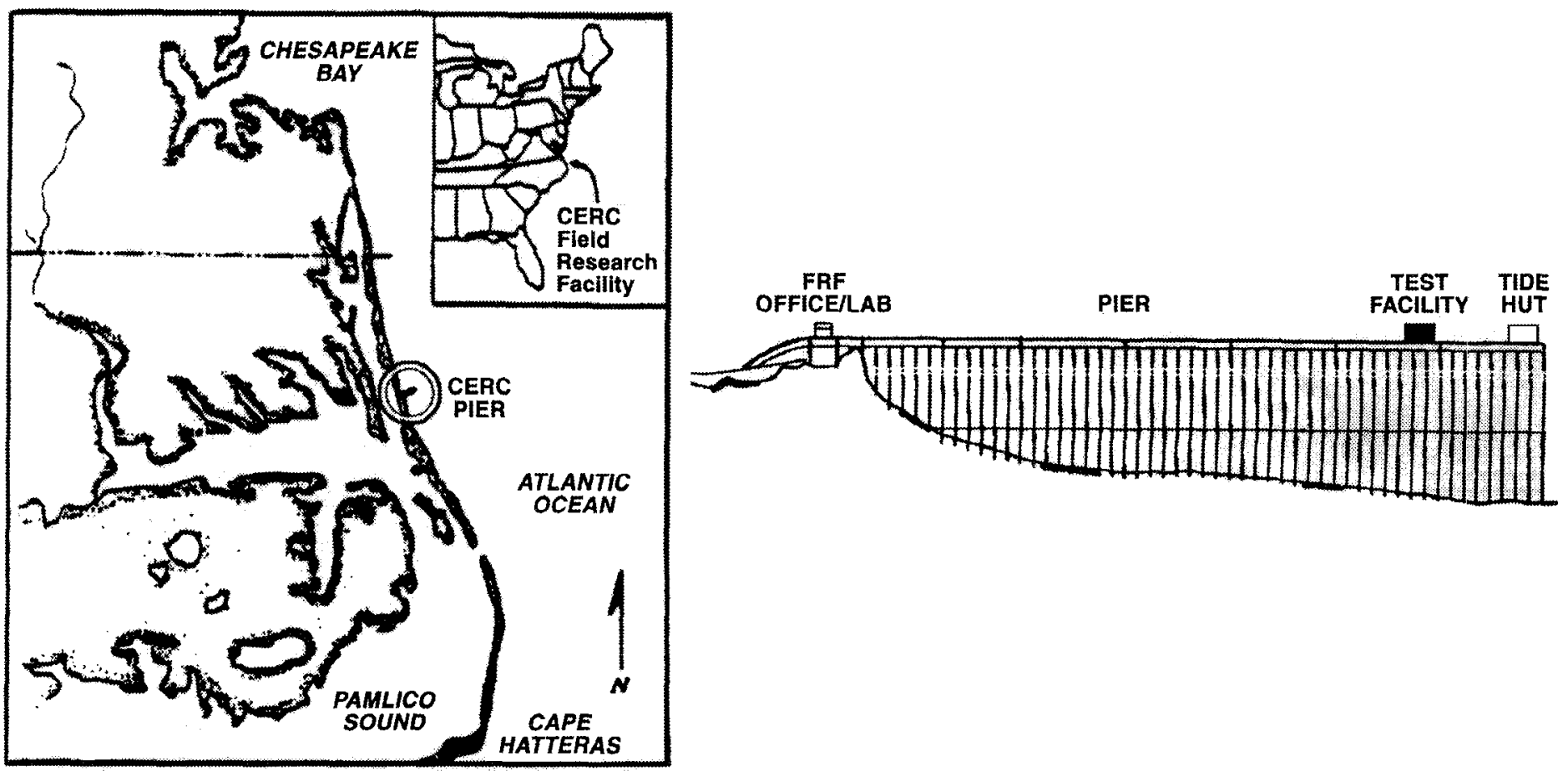

Fig. 3. Corps of Engineers Field Research Facility 
185 water level measurement sites along the coastlines of the United States, in the Great Lakes, and on some Pacific islands. The sites provide the data required to fulfill one of NOS's missions - to observe and predict tides and water levels and to obtain and archive data.

Most of the sites are equipped with NOS's next generation water level measurement systems consisting of a Sutron 9000 Data Collection Platform (DCP) using an Aquatrak® airacoustic water level sensor manufactured by Bartex. The primary method of data telemetry from the DCP is via the Geostationary Operational Environmental Satellite (GOES) Data Collection System (DCS) on a 3-hour reporting interval. Most sites also have telephone telemetry available as a backup and for real-time applications. Water level is the primary measurement at all of the sites, but many have additional sensors installed, such as water and air temperature and barometric pressure. Recent upgrades were developed, with support from the National Weather Service (NWS), to add to the capability for eventtriggered random reporting. This was implemented at 40 west coast and Pacific island sites in support of the NWS Tsunami Warning Program and is being implemented at the Great Lakes and east and Gulf coast sites in support of the NWS Storm Surge Warning Program. Data from the NOS water level network is available on the Internet at http://www.olld.nos.noaa.gov.

The Sutron DCP has the capacity to accept a variety of oceanographic and/or meteorological sensors. The DCP can store sensor transfer functions; thus, the data stored and telemetered usually are in engineering units and consist of a mean value with computed standard deviation over the measurement interval. NOS also can modify the DCP software to run special experiments and to accommodate operationally new sensor types and/or sampling schemes that were not envisioned in the original DCP design.

\section{B. WES Network}

The WES is responsible for permits and management of navigation and flood protection projects around the United States. WES supports this mission through research and development in the technical areas of coastal, hydraulic, geotechnical, structural and environmental engineering, and information technology. Part of this support is through their Field Wave Gaging Program (FWGP), a network of wave, current, and water level monitoring stations around the United States' coastline.

The COE network consists of approximately 50 monitoring stations in coastal waters and harbors around the United States. Most of the stations are bottom-mounted pressure arrays in shallow ( 5 to $20 \mathrm{~m}$ ) water, though some buoys and platformmounted stations are operated in deeper water as well. Their primary mission is to collect directional wind wave and long wave data for planning, designing, and managing coastal projects. Currents and meteorological parameters are also measured at selected stations, and a high-accuracy, offshore tide gauge is under development. Each multichannel station is connected via submarine cable or radio to a shore station, then via a land or cellular phone to one of several data collection centers for analyses, quality control, storage, and dissemination over the World Wide Web (WWW). Data are also stored in the underwater platform and at the shore station for later retrieval in case of telemetry failure. Routine data retrieval occurs at 1- to 4hour intervals, though real-time networking is available for observing episodic events (e.g., hurricanes, tsunamis), military operational applications, and diagnostics.

\section{NDBC Network}

NDBC is part of NWS in NOAA and supports the NWS mission to provide warnings and forecasts. NDBC operates 62 moored buoys and 52 fixed platforms called the CoastalMarine Automated Network (C-MAN). These stations are in coastal and offshore marine waters around the United States, the Great Lakes, and the western tropical Pacific. The stations are fully automated and report meteorological and oceanographic data hourly through GOES. The data are distributed in real time and are available on the Internet at http://www.ndbc.noaa.gov. Data collected include wind speed, direction, and gusts; barometric pressure; air and sea surface temperature; and (from all moored buoys and some C-MAN stations) wave spectrum. Other measurements on selected stations include continuous winds, relative humidity, currents, salinity, and solar radiation.

The moored buoy fleet consists of 3-, 10-, and 12-m discus-shaped hulls and a 6-m Naval Oceanographic and Meteorological Automated Device (NOMAD) boat-shaped hull. The 10-, 12-, and 6-m hulls are used primarily in deep waters, while the $3-\mathrm{m}$ discus is typically used in shallow waters over the continental shelves. C-MAN sites are fixed platforms along the coasts and are weather stations mounted on lighthouses, piers, offshore towers, and stand-alone installations designed and established for this purpose. Payloads on NDBC platforms are powered from secondary batteries with solar charging. They are designed to operate continuously for 2 years. The payload is used for data acquisition, control, processing, and reporting via GOES. Additionally, NDBC designed and produced a special NDBC Ocean Sensor Interface Controller (NOSIC) to accept additional sensors (Computer Sciences Corporation, 1995). The NOSIC is used to power the additional sensors; collect, process, and store data for hourly reporting through GOES; and transfer raw data to a time-series data logger called the MARK II.

\section{SENSOR TEST FACILITY}

The ocean sensor test facility was established on the FRF pier in April 1995. It consists of the following:

- An NOS laboratory for water level measurements $(2 \times 3 \times 2.4 \mathrm{~m})$

- Two environmental laboratories (each $6 \times 3.3 \times 2.4 \mathrm{~m}$ )

- A deployment system for oceanographic sensors

- A 12.2-m sensor tower for meteorological sensors and above-water oceanographic sensors

- A WES Remote Terminal Unit (RTU) for underwater data collection

- An NOS water level station

- An NDBC C-MAN weather station

The two large laboratories, shared by NDBC, COE, and the Navy (which shares the laboratory but does not operate an established network for in situ monitoring) are located $12 \mathrm{~m}$ 
from the end of the pier; the NOS water level laboratory is at the end on the southeast corner (Fig. 4). The NDBC portion of the laboratories is used for the sensor testing facility and contains a wet laboratory and electronics/storage area. The laboratory is temperature controlled with electrical power, telephone lines, computer access, work benches, storage cabinets, running water, and chemical disposal methods. A full description of the facility is presented by Teng (1997). A brief summary is presented below.

The oceanographic sensor deployment device is outside the laboratory on the south side of the pier (Fig. 5). Water depth is $7 \mathrm{~m}$. The device consists of a track/cart/arm assembly with a winch to raise and lower the device eliminating the need for divers (Fig. 6). A hexagonal-shaped cart and extended arms are used to mount the instruments.

The antenna for data transmission, solar panels for charging secondary batteries, and atmospheric sensors are installed on top of the laboratory and the sensor tower. A sensor swing arm is attached to the tower and extends outward over the water. The arm is designed so that it can be moved over the laboratory to install and remove instruments easily (Fig. 5). The height of the swing arm positions the sensors $4.6 \mathrm{~m}$ above the pier.

A data acquisition system (based on a Pentium 166 PC) is housed in the laboratory; it collects and transfers data to NDBC via phone line. The software was custom designed to record data from any sensor having analog or digital (parallel or serial) outputs. Power for each sensor is supplied by programmable DC power supplies controlled by GPIB bus and the PC. NDBC can control the system remotely to retrieve data files and update software.

The ocean sensors are interfaced to the C-MAN payload through the NOSIC. The NOSIC powers each sensor, allowing for warm up, and collects a specified time series of data. Data from each sensor are sampled at a rate of $6 \mathrm{~Hz}$ for 3 minutes. At the end of data acquisition, the data are processed to calculate a mean and standard deviation for an hourly GOES transmission. The raw data are also transferred to the MARK II for later retrieval. The NOSIC is also interfaced to a terminal (PC), modem, and a Global Positioning System for accurate timing. A block diagram is shown in Fig. 7.

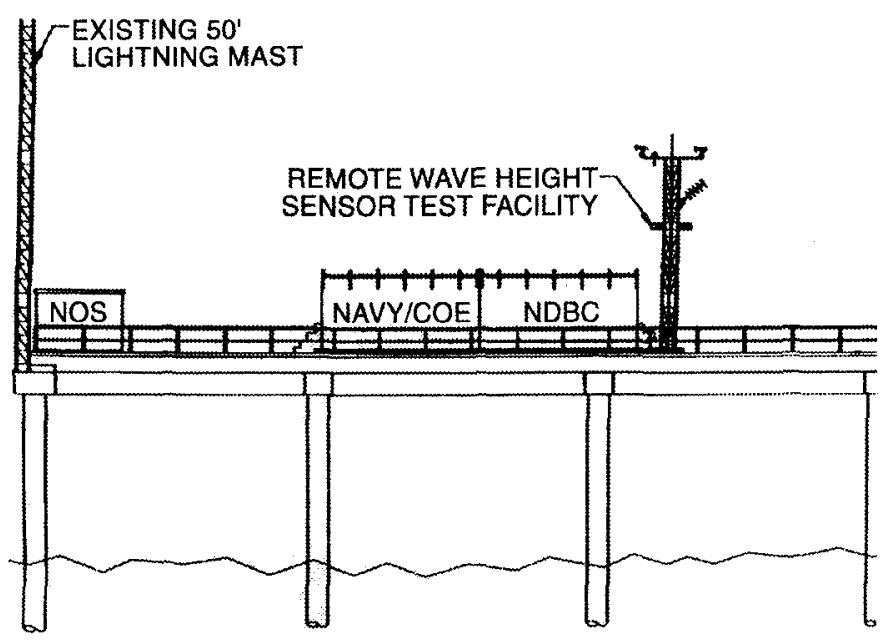

Fig. 4. Location of the Sensor Test Facility on the FRF pier (looking south)
The facility was used to test a suite of oceanographic sensors being prepared for future buoy or C-MAN deployment in support of the National Aeronautics and Space Administration's (NASA) Sea-viewing Wide Field-of-view Sensor (SeaWiFS) program. The purpose was to test the entire system from data collection to transmission. Sensors tested include an AC-9 chlorophyll absorbance meter, a SeaBird conductivity/ temperature/depth (CTD) sensor, an oxygen sensor, a fluorometer, and in-water and above-water radiometers. As part of the test, biofouling was monitored. The sensors were deployed from November 1996 to June 1997. They are being evaluated for performance, durability, reliability, data quality, and cost of operation. Other sensors tested include a laser wave gauge, Gill anemometer, and pressure sensor.

\section{V.FUTURE WORK}

The next step is to develop a common interface standard for use with the available platforms. When developed, it will be integrated into the WES/NOS/NDBC platforms at the FRF, tested, and evaluated. An outcome of this will be to produce

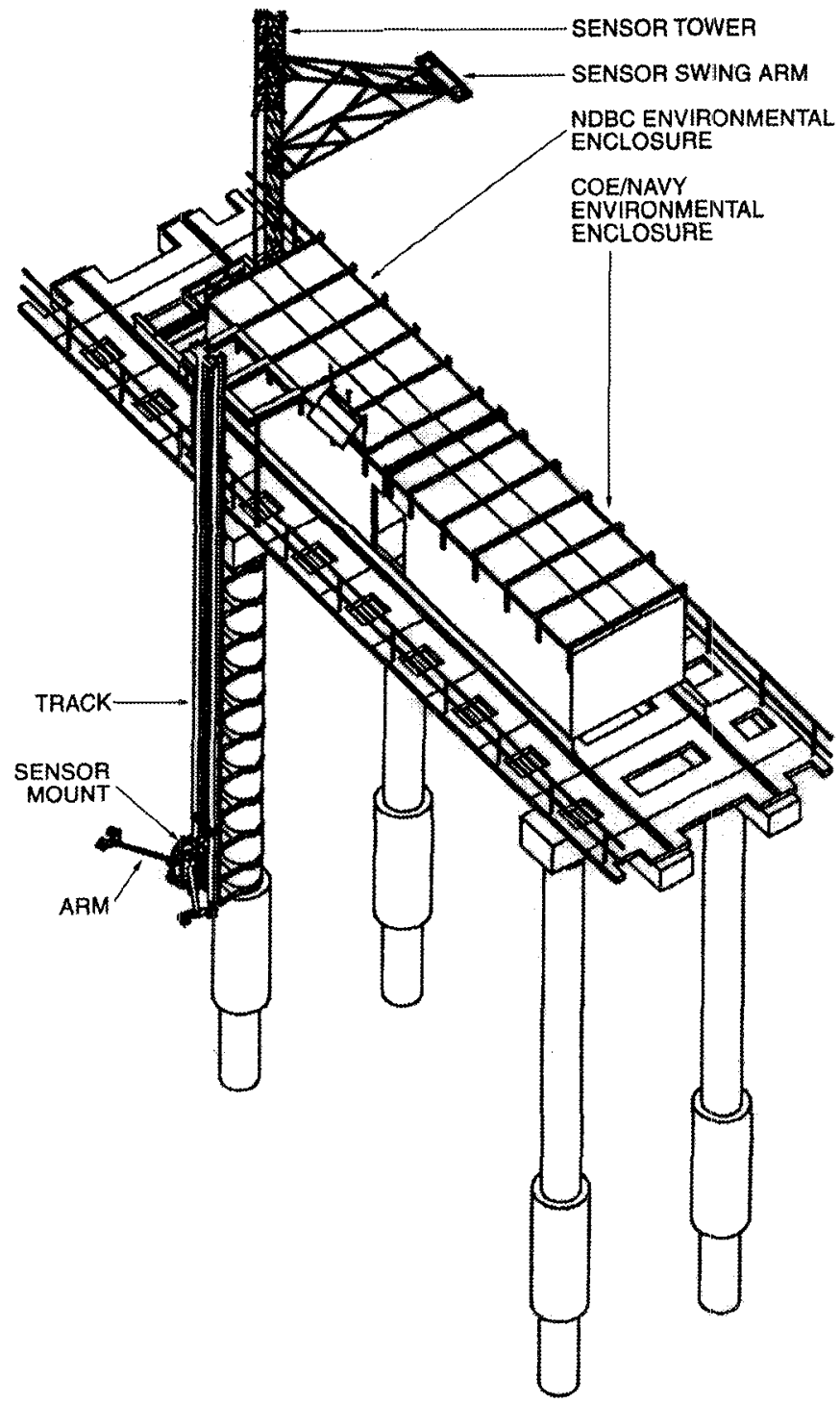

Fig. 5. Isometric view of the test facility 


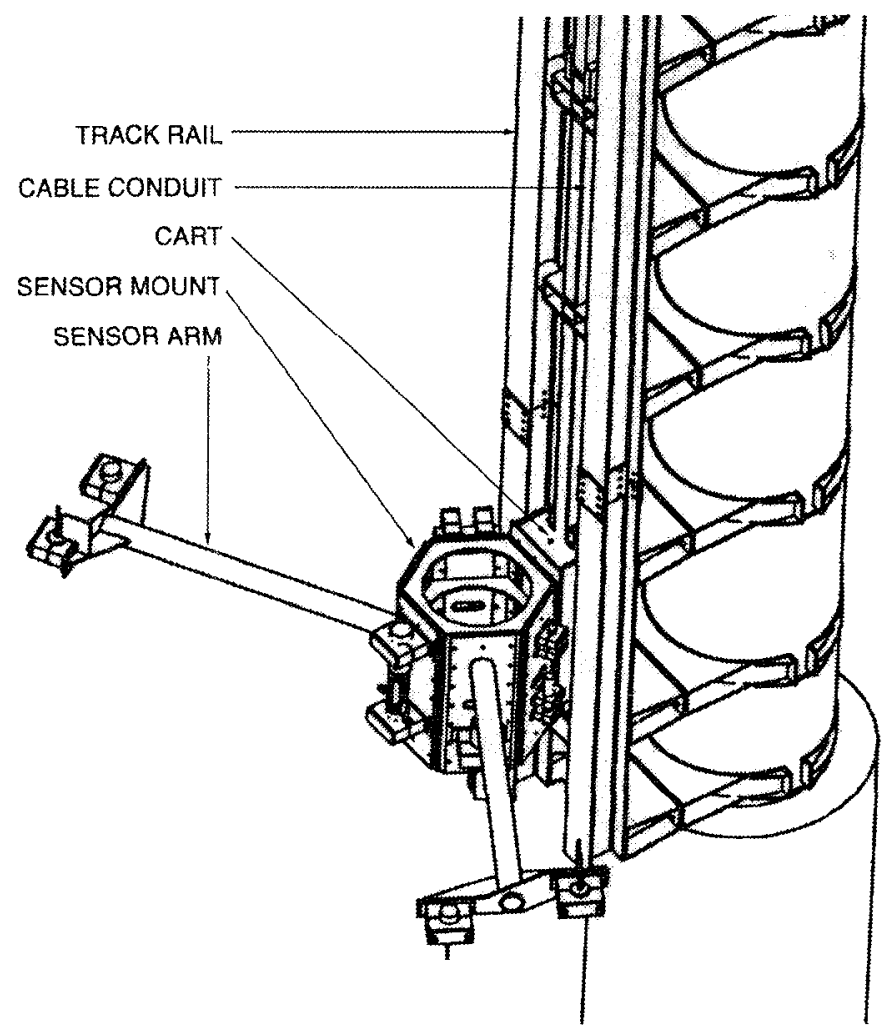

Fig. 6. Isometric view of the track/cart/arm assembly

compatible data products. This provision is necessary for implementing any large-scale monitoring program, particularly when using platforms of opportunity such as those operated by the WES, NOS, and NDBC. For such a program, sensor output needs to be integrated into a viable data management system with provisions for routine sampling, telemetry, analysis, quality control, distribution, and archival of the measurements.

The site is available to investigators for sensor testing. Each sensor will be evaluated as for the NASA SeaWiFS test. The three organizations are working toward developing this facility as an environmental sensor certification site.

\section{CONCLUSIONS}

An increasing need exists for continuous collection of oceanographic data for scientific research and regulatory obligations to monitor short- and long-term natural variability within the context of human impact, especially in coastal waters. The establishment of this site will enable environmental managers and scientists to develop, assess, and evaluate the capabilities of oceanographic and meteorological sensors to meet the requirements of long-term, unattended monitoring programs.

\section{REFERENCES}

Birkemeier, W.A., Miller, H.C., Wilhelm, S.D., DeWall, A.E., and Gorbics, C.S., 1985, A user's guide to the Coastal Engineering Research Center's (CERC's) Field Research Facility, IR CERC-85-1, Dept. of the Army, Watersways Exper. Sta., COE, 121 pp.

Computer Sciences Corporation, 1995, NDBC participation in SeaWiFS, phase I - design/feasibiliy report, CSC, ATD, Stennis Space Center, MS, $45 \mathrm{pp}$.

Teng, C.C., 1997, NDBC Atmospherical and Oceanographic System Test Facility, MTS Tech. Wkshp., April, 6 pp.

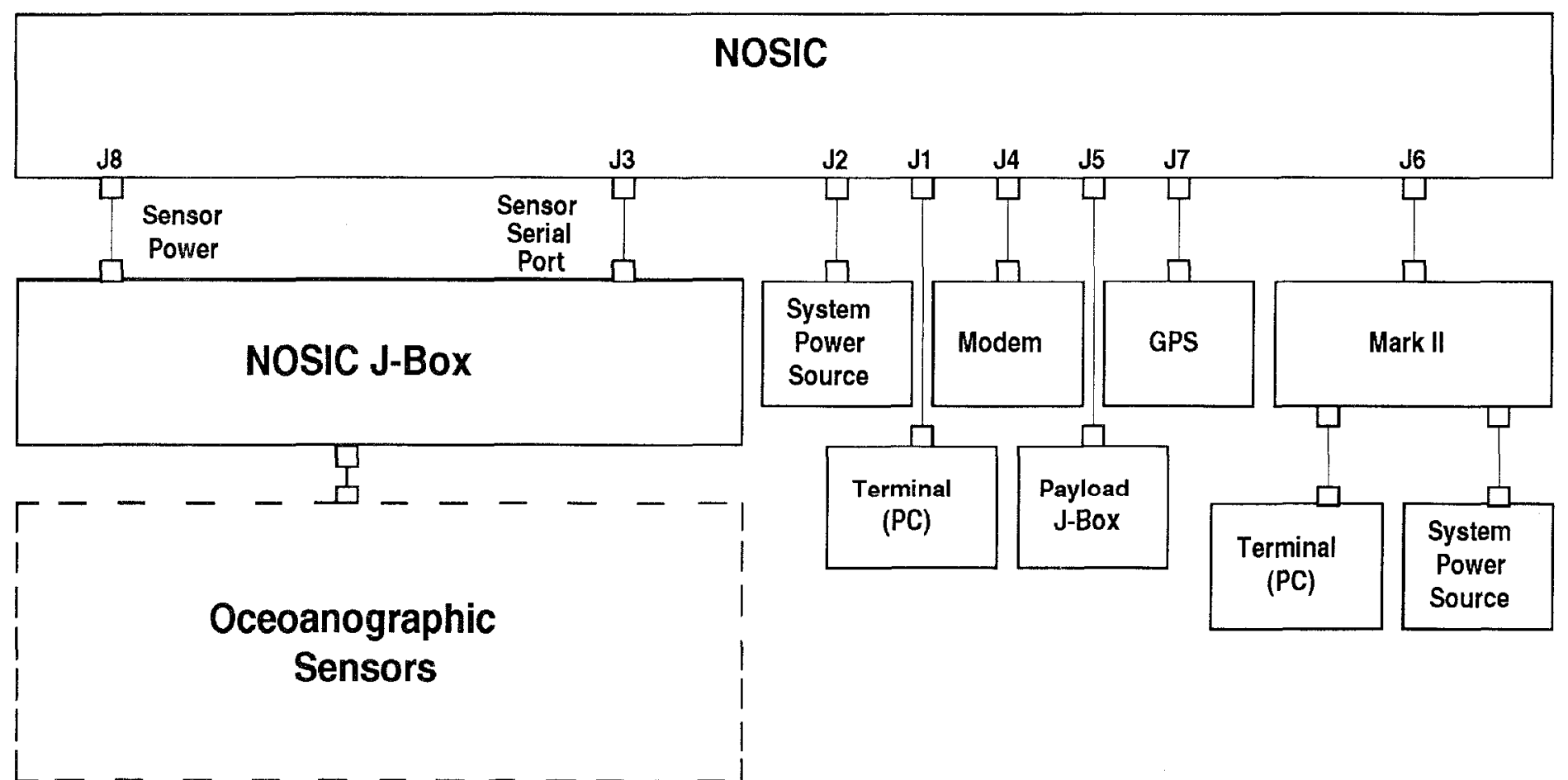

Fig. 7. Block diagram of the NOSIC system 